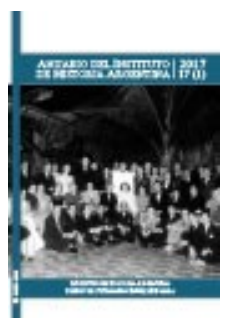

Anuario del Instituto de Historia Argentina, vol. 17, nº 1, e041, junio 2017.

ISSN 2314-257X

Universidad Nacional de La Plata.

Facultad de Humanidades y Ciencias de la Educación.

Centro de Historia Argentina y Americana

\title{
Una aproximación a los orígenes de la administración penitenciaria federal. Las "comisiones de cárceles" y el Proyecto de Reformas de Claros y Muratgia (1890-1912)
}

\author{
An approach to the origins of the federal penitentiary \\ administration. The "prison commissions" and the Muratgia-Claros \\ project (1890-1912)
}

\section{Luis González Alvo *}

* CONICET - Instituto de Investigaciones Históricas Dr. Ramón Leoni Pinto, Argentina | Igonzalezalvo@gmail.com

\section{PALABRAS CLAVE}

Sistema penitenciario

Comisiones de cárceles

Construcción estatal

Armando Claros

Catello Muratgia

\section{KEYWORDS}

Penitentiary system

Prison commissions

State building

Armando Claros

Catello Muratgia

\section{RESUMEN}

En este trabajo se presenta una aproximación a los orígenes de la administración penitenciaria federal, a través del análisis de las "comisiones de cárceles”, formadas entre 1890 y 1911. Se abordan las trayectorias de dos reconocidos penitenciaristas que formaron parte de la comisión de 1911Catello Muratgia y Armando Claros- y elaboraron un importante informe titulado Proyecto de Reformas Carcelarias. Con tales fines, se presenta un sucinto panorama de las cárceles federales hacia 1890, se abordan aspectos biográficos de los autores mencionados y se analiza su aporte específico a través del proyecto de 1911. En suma, con este trabajo se pretende contribuir a ampliar el conocimiento sobre los orígenes de la administración penitenciaria federal, las comisiones de cárceles y algunos de los cuadros superiores durante parte de la etapa “descentralizada”, es decir, anterior a la ley $n^{\circ} 11.833$ (1933).

\section{ABSTRACT}

This paper analyzes the origins of the federal penitentiary administration through the analysis of the "prison commissions" formed between 1890 and 1911. Emphasis is given to the trajectories of two recognized experts on the matter who were part of the 1911 commission: Catello Muratgia and Armando Claros. They produced an important report titled Proyecto de Reformas Carcelarias. For these purposes, is included a brief overview of the federal prisons around 1890 and biographical aspects of the mentioned authors. In sum, this paper makes a contribution in order to expand our knowledge about the penitentiary administration origins, the work of the prison commissions and the trajectories of high ranks officers at its “decentralized” phase, before the law n 11.833 (1933). 


\section{Introducción}

En 1911, mientras se discutía en el Congreso Nacional la reforma del Código Penal, el ministro de Justicia e Instrucción Pública, Juan Manuel Garro, solicitó a Armando Claros, director de la Penitenciaría Nacional, a Catello Muratgia, director del Presidio de Ushuaia, y a Diego González, inspector general de justicia, un informe sobre la situación de las prisiones en el país y un plan de reforma para su mejora. La iniciativa de formar una comisión de especialistas para considerar el problema no constituía una novedad, sino que se trataba de un recurso empleado desde fines del siglo XIX, a partir de la consolidación del Estado nacional.

Pierre Bourdieu caracteriza a la creación de comisiones como una doble acción estatal, ya que implica, simultáneamente, el nombramiento de un conjunto de personas capacitadas para realizar una función determinada y el reconocimiento oficial de un "problema digno de ser tratado por personas dignas de tratar los problemas públicos" (Bourdieu, 2014, p. 42)ํㅗ․ Se trataba de una estrategia corriente de los "reformistas liberales" que dominaban por entonces el aparato estatal nacional. Tal como ha señalado Eduardo Zimmermann, aquella generación de dirigentes e intelectuales buscó replantear la organización institucional mediante reformas legislativas. Tenían la convicción de que la política parlamentaria era el ámbito propicio para la búsqueda de soluciones al conflicto social, mediante una concepción cientificista que buscaba un punto intermedio entre el laissez faire ortodoxo y el socialismo de Estado (Zimmermann, 1995, p. 15).

Las comisiones de cárceles comenzaron a funcionar en 1890 y pueden ser consideradas como parte de un incipiente desarrollo de un sistema penitenciario federal. Este desarrollo se insertaba en un proceso mayor de construcción estatal- que buscaba centralizar la administración judicial e implementar un efectivo monopolio de la violencia, escasamente alcanzado hasta entonces en buena parte del territorio nacional $\underline{2}$. Asimismo, se estimaba que el proyecto penitenciarista -cuya importancia gozaba de consenso intelectual y social- contribuiría a la capacidad de externalizar el poder del Estado nacional en zonas en disputa con otros Estados, fundamentalmente la Patagonia y el $\mathrm{Chaco}^{\underline{3}}$. De allí la iniciativa de instalar en todos los territorios nacionales al menos un establecimiento penal anexo a la justicia letrada. En muchos casos, las cárceles de los territorios fueron centros de colonización de esos espacios; el más emblemático es el del Presidio de Ushuaia en Tierra del Fuego (García Basalo, 1981).

Hacia 1890 sólo existían dos cárceles federales, ambas en la Capital y construidas por el gobierno provincial de Buenos Aires -habían sido nacionalizadas junto a la ciudad en 1880-, la Penitenciaría Nacional y la Cárcel Correccional ${ }^{4}$. Entre 1895 y 1896 se nombraron alcaides, celadores y "comisiones de construcción de cárceles” en siete de los nueve territorios nacionales: Misiones, Chaco y Formosa, en el norte; La Pampa, en el centro, y Neuquén, Chubut y Río Negro, en el sur. Los dos restantes, Tierra del Fuego y Santa Cruz, comenzaron sus construcciones en 1896 y $1899 \stackrel{5}{5}$.

\section{Cuadro 1. Espacios de reclusión de la órbita federal hacia fines del siglo XIX*}

\begin{tabular}{|l|l|c|}
\hline Institución & Ubicación & Inicio de obras \\
\hline Penitenciaría Nacional & Capital Federal & $\begin{array}{c}1880 \\
\text { (nacionalización) }\end{array}$ \\
\hline Cárcel Correccional de Varones & Capital Federal & $\begin{array}{c}1880 \\
\text { (nacionalización) }\end{array}$ \\
\hline Cárcel Correccional de Mujeres & Capital Federal & $\begin{array}{c}1880 \\
\text { (nacionalización) }\end{array}$ \\
\hline Cárcel de Posadas & T.N. de Misiones & $1895 / 1896$ \\
\hline Cárcel de Formosa & T.N. de Formosa & $1895 / 1896$ \\
\hline
\end{tabular}




\begin{tabular}{|c|c|c|}
\hline $\begin{array}{l}\text { Cárcel de General Acha } \\
\text { (En } 1904 \text { se habilitó la cárcel de Santa } \\
\text { Rosa de Toay) }\end{array}$ & T.N. de La Pampa Central & $1895 / 1896$ \\
\hline $\begin{array}{l}\text { Cárcel de Chos-Malal } \\
\text { (En } 1904 \text { se habilitó la cárcel de } \\
\text { Neuquén) }\end{array}$ & T.N. de Neuquén & $1895 / 1896$ \\
\hline Cárcel de Viedma & T.N. de Río Negro & $1895 / 1896$ \\
\hline Cárcel de Resistencia & T.N. del Chaco & $1895 / 1896$ \\
\hline Cárcel Pública de Rawson & T.N. del Chubut & $1895 / 1896$ \\
\hline Cárcel de Rio Gallegos & T.N. de Santa Cruz & 1899 \\
\hline $\begin{array}{l}\text { Cárcel de Reincidentes de Ushuaia } \\
\text { (El nuevo edificio, diseñado por } \\
\text { Muratgia, comenzó a construirse en } \\
1902 \text { y fue habilitado en 1909) }\end{array}$ & T.N. de Tierra del Fuego & 1896 \\
\hline \multicolumn{3}{|c|}{$\begin{array}{l}\text { * La mayoría de estas cárceles comenzaron a funcionar a la vez que eran construidas por los propios } \\
\text { reclusos y llevaron muchos años hasta ser concluidas. El } 6 \text { de abril de } 1895 \text { se estableció por decreto } \\
\text { el Reglamento provisorio de las Cárceles de los Territorios Nacionales. RNRA, primer semestre de } \\
\text { 1895, pp. 555-558. Boletín Oficial de la República Argentina, } 6 \text { de abril de } 1895 \text { (en adelante } \\
\text { BORA). }\end{array}$} \\
\hline \multicolumn{3}{|c|}{$\begin{array}{l}\text { Fuentes: “Decreto nombrando fiscales defensores y alcaides de cárcel de los Territorios Nacionales”, } \\
\text { RNRA, primer semestre de 1895, pp. 211-212; “Acuerdo nombrando una comisión ad-honorem, } \\
\text { para varios territorios nacionales, encargada de correr con la construcción de los edificios destinados } \\
\text { á Cárceles y Juzgados letrados de los mismos”, RNRA, segundo semestre de 1895, pp. 829-830; } \\
\text { "Decreto designando el territorio de la Tierra del Fuego para la ejecución de la ley n.3.335”, RNRA, } \\
\text { primer semestre de 1896, p.114. }\end{array}$} \\
\hline
\end{tabular}

Los años que transcurrieron luego del comienzo de las edificaciones carcelarias en los territorios fueron de grandes dificultades. Las quejas más corrientes de los directores de las cárceles territorianas se referían a los permanentes problemas edilicios, la escasez de recursos y la falta de personal $\stackrel{6}{6}$. Sin embargo, al finalizar la primera década del siglo XX, en el ámbito penitenciarista no cabían dudas de que un plan de mejoras no podía limitarse a solucionar los problemas edilicios -que eran graves-, sino que también debía orientarse hacia la creación de una administración centralizada encabezada por especialistas ${ }^{7}$. A poco más de un año de la iniciativa de Garro, el 31 de diciembre de 1912, los miembros de la comisión presentaron un informe

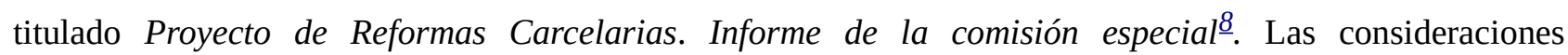
preliminares llevaban la firma de los tres miembros, pero el grueso del trabajo estaba compuesto por dos estudios, uno de Armando Claros y el otro de Catello Muratgia. Aquel proyecto permite establecer un mirador desde el cual es posible analizar algunos aspectos del lento y complejo proceso de ensayos institucionales que fue sentando las bases para la creación de una administración penitenciaria centralizada. $\mathrm{Al}$ mismo tiempo, sus autores encarnan las ideas penales más avanzadas de la época, lo cual se observa en sus ambiciosos proyectos de reorganización institucional y edilicia de las cárceles federales.

Con el propósito de presentar una aproximación a los orígenes de la administración penitenciaria federal se analizará la forma particular que tuvo el Estado liberal de encarar la reforma a través de la conformación de “comisiones de especialistas”, entre 1890 y 1911. Luego se ensayará un sucinto repaso biográfico de dos figuras centrales del penitenciarismo argentino -Claros y Muratgia - con el que se espera contribuir a ampliar nuestros conocimientos acerca de los cuadros superiores de la administración penitenciaria argentina en su 
etapa “descentralizada”, es decir, anterior a la ley n ${ }^{\circ} 11.833$ de Organización Carcelaria y Régimen de la Pena $(1933)^{9}$. Finalmente se analizará el proyecto de reforma de 1912 a través de sus consideraciones generales y de los planes de reorganización administrativa y renovación edilicia que propone $\frac{10}{0}$.

La historia de la construcción del sistema penitenciario federal durante este período ha sido escasamente estudiada $\frac{11}{}$. En este sentido, deben mencionarse los trabajos considerados fundacionales de la historiografía de la prisión argentina, a saber, los de Ricardo Salvatore (1996) y Lila Caimari (2004). Posteriormente, inspiradas en aquellos estudios -que tratan sobre las dos cárceles federales más importantes-, se produjeron nuevas investigaciones sobre instituciones federales periféricas, como las de Ernesto Bohoslavsky y Fernando Casullo (2008), quienes exploraron los límites del control social entre 1880-1930 y plantearon las particularidades del sistema penitenciario patagónico. Bohoslavsky también ha subrayado las diferencias materiales y presupuestarias entre las cárceles de los Territorios Nacionales, la Penitenciaría Nacional y la Cárcel de Ushuaia en las primeras décadas del siglo XX (2005, 2009). Más recientemente, Pablo Navas, en su tesis doctoral sobre la construcción de la soberanía en Santa Cruz (2012) condensa sus investigaciones previas acerca de la cárcel de Río Gallegos: la relación entre el periodismo y la cárcel, el trabajo de los presos y la profesionalización del cuerpo de guardias (2009; 2010a y 2010b). Por último, Valeria Flores presenta un panorama general de la construcción y funcionamiento de las cárceles pampeanas de General Acha y de Santa Rosa (2015).

La construcción de las primeras cárceles provinciales ha sido estudiada por Abelardo Levaggi (2002), Carolina Piazzi (2011), Alejo García Basalo (2013a y 2017), Luis González Alvo (2013, 2015) y Milena Luciano (2013, 2014). Con la presente investigación se pretende contribuir a establecer un punto de comparación y de diálogo entre los orígenes de la centralización administrativa federal y provincial, casos que no han sido abordados hasta la fecha. Por último, cabe mencionar que durante el período analizado la justicia federal -de la cual dependía el sistema penitenciario- se encuentra en un proceso de centralización general que ha sido analizado por Eduardo Zimmerman (2007). El debate producido durante el Centenario en torno a la forma de implementación del sistema federal y la centralización administrativa puede verse en Paula Alonso y Beatriz Bragoni (2015)ํㅗ․

\section{Las “comisiones de cárceles” de 1890 a 1906}

En su estudio sobre el nacimiento de la penitenciaría en Latinoamérica, Ricardo Salvatore y Carlos Aguirre sugieren la existencia de un fenómeno regional cíclico de entusiasmo, descreimiento e interés renovado acerca de las posibilidades reales de aplicación de la reforma penitenciaria (Salvatore y Aguirre, 1996, p. 9). En la Argentina podría observarse tal ciclo si se reconociera una fase "entusiasta” entre fines del siglo XIX y comienzos del XX, durante las administraciones de O’Gorman y Ballvé frente a la Penitenciaría Nacional, y de Duffy frente al Asilo Correccional de Menores $\underline{13}$. El "descreimiento" -podría señalarse- crece casi simultáneamente a esas administraciones, cimentado por sus propias falencias y por las experiencias de sus pares de las demás instituciones de reclusión del país al sufrir los obstáculos materiales para la aplicación de parámetros cientificistas. En un principio, este panorama -que a los ojos de los especialistas era desoladorera observado por las autoridades políticas con menor preocupación, aunque por momentos se observaban brotes de interés renovados por la cuestión carcelaria. En varias ocasiones se discutieron distintas posibilidades de creación de penitenciarías regionales, nacionalización de cárceles provinciales existentes y se crearon comisiones de especialistas para inspeccionar las cárceles y analizar los medios más convenientes de encauzar la reforma a nivel nacional $\underline{14}$.

La primera comisión de cárceles de la que tenemos registro fue creada en septiembre de 1890 por decreto del presidente Carlos Pellegrini. Nació originalmente como un intento de remover de la Penitenciaría a los 
menores y mujeres que eran allí alojados y reorganizar sus espacios de reclusión específicos $\underline{15}$. Sus primeros integrantes fueron tres ciudadanos "idóneos": Francisco Ayerza, Guillermo Udaondo y Angel Roverano $\underline{16}$. Al mes siguiente de haber sido creada, se cambió su nombre a Comisión de cárceles y casas de corrección, se establecieron sus atribuciones y se fijó una duración de dos años en el cargo para sus miembros. El decreto detalla siete funciones para la Comisión:

1. Ocuparse de las licitaciones y contratos para proveer los establecimientos.

2. Suscribir los contratos de provisión según la Ley de Contabilidad.

3. Vigilar la higiene general y alimentación de los detenidos.

4. Pagar directamente a los contratistas y rendir cuenta a la Contaduría General.

5. Autorizar los pedidos de artículos del consumo ordinario.

6. Supervisar el cumplimiento de los reglamentos.

7. Organizar la enseñanza en cada establecimiento y ser el nexo con las asociaciones filantrópicas $\frac{17}{\text {. }}$

Los miembros de la comisión fueron variando rápidamente. El 10 de noviembre de 1890, Udaondo renunció

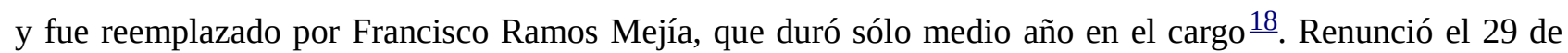
julio de 1891 y fue reemplazado por Emilio Martínez de Hoz. Posteriormente Norberto Fresco reemplazó a Ángel Roverano.

En 1892, cumplidos los dos años de función de la comisión, el presidente Luis Sáenz Peña decretó la renovación de los cargos de sus miembros por dos años más $\underline{19}$. En mayo de 1893 estalló un conflicto entre los miembros de la comisión y los directivos de la Penitenciaría Nacional por "confusión de atribuciones" entre ambos. La disputa culminó con la exoneración del vicedirector y el alcaide de la Penitenciaría por dar “ejemplos de indisciplina y ordenar y tolerar infracciones al Reglamento por parte de presos y empleados” 20 . El director, coronel José María Morales, solicitó su jubilación en medio del conflicto -fue reemplazado por Francisco Wright- y se nombró una comisión investigadora formada por Juan Antonio Argerich, Augusto Coelho y Osvaldo Piñero para que estudiasen el estado de la cárcel e indicasen "las medidas que reputen necesarias para asegurar su mejor funcionamiento”르. Por último, el 11 de agosto de 1893, se zanjó el asunto colocando al mismo Wright como director de la Penitenciaría y presidente de la Comisión de Cárceles르.

Durante el año 1894 se formó una nueva comisión, conformada por Arturo Gramajo, Ernesto Bosch y Antonio Dellepiane. En agosto presentaron un proyecto de ley que proponía ampliar considerablemente sus funciones para convertirla en una superintendencia de cárceles federales y, de esa manera, zanjar el “conflicto de atribuciones” con la Penitenciaría Nacional y dirigir las nuevas cárceles que comenzaban a construirse en los Territorios Nacionales $\underline{23}$. El proyecto contemplaba además que se le atribuyese a la comisión facultades de fiscalización de las cárceles provinciales y de "los establecimientos de carácter privado en los cuales se detengan ó recluyan personas”. Sobre la última disposición, los autores del reglamento declaraban que si bien podía "constituir una novedad en nuestra legislación, no lo es para otras naciones que la tienen establecida con resultados indiscutibles”. Apoyándose en la experiencia del Congreso Penitenciario celebrado en Estocolmo en 1878, Gramajo, Bosch y Dellepiane señalaron que no era "solamente útil sino también necesario que haya en el estado un poder central que dirija y vigile todas las prisiones sin excepción, como asimismo todos los establecimientos destinados á la reclusión de menores delincuentes”느. Otras fuentes de igual importancia para redactar el proyecto fueron el Real decreto de 1888, que había creado en España las Juntas de Prisiones y la obra del director general de prisiones de Francia, 
Louis Herbette. Entre las funciones de la comisión se incluyó asesorar al gobierno "en cuestiones relacionadas con el régimen de las cárceles, proyectar reglamentos para el funcionamiento interno de las mismas, iniciar reformas en materia de régimen carcelario y organizar la estadística”. Finalmente, el proyecto no fue aprobado y los tres integrantes de la comisión presentaron sus renuncias el 13 de mayo de 1895. Fueron reemplazados por Julián L. Aguirre, Augusto J. Coelho y Mariano T. Saubidet $\underline{25}$.

En 1895, paralelamente a la Comisión de Cárceles de la Capital, se crearon comisiones ad honorem en cada territorio nacional para que se encargasen de la construcción de cárceles y juzgados letrados, compuestas por el gobernador del territorio, el alcaide de la cárcel -luego el director cuando se hubo creado el cargo- y el fiscal del juzgado. $\underline{\underline{26}}$ Cuando las comisiones encontraron problemas para licitar las obras se firmó un acuerdo para autorizarlas a realizar directamente los contratos sin pasar por Contaduría General $\underline{27}$. Hacia 1902 se ampliaron las atribuciones de dichas comisiones mediante un decreto del Poder Ejecutivo y pasaron a llamares Comisiones de Vigilancia y Construcción. Además de continuar a cargo de la construcción de las cárceles y juzgados, sus nuevas funciones incluían:

1. Ejercer vigilancia sobre la higiene y régimen carcelario, y especialmente sobre la alimentación de los detenidos, controlando la calidad y cantidad de los artículos.

2. Proponer al Ministerio de Justicia la separación de los empleados que faltaren a sus deberes exponiendo las razones y antecedentes.

3. Vigilar el fiel cumplimiento de las disposiciones y Reglamento que rigen en la Cárcel o proyectar su reforma.

4. Propender a la conveniente colocación y radicación en el territorio de los presos puestos en libertad, ofreciendo a los que voluntariamente aceptaran su patronato, la protección compatible con los recursos de que se dispusiere ${ }^{28}$.

La Comisión de Cárceles y Casas de Corrección fue finalmente disuelta en 1899로․ De esta manera concluyó el primer intento de crear un organismo centralizador de los establecimientos de reclusión. Sin embargo, algunos años más tarde, la superintendencia de las cárceles federales fue otorgada a la Inspección General de Justicia (IGJ), que dependía del Ministerio de Justicia e Instrucción Pública $\underline{30}$. A partir de entonces la licitación de alimentos, firma de contratos y demás atribuciones de las comisiones de cárceles pasaron a ser ejercidas por el IGJ. Asimismo este organismo impulsó visitas periódicas de sus inspectores a los Territorios Nacionales para que supervisaran el funcionamiento de la justicia, registro civil y educación de sus ciudades más importantes. Uno de los funcionarios más destacados fue Ramón Nieto Moreno, quien entre 1900 y 1911 viajó en varias ocasiones a todos los territorios nacionales para inspeccionar el funcionamiento de las instituciones dependientes del Ministerio de Justicia $\underline{31}$.

En 1905, durante la presidencia de Quintana, se creó el cargo de Inspector General de Cárceles y en 1906 se designó a Nieto Moreno $\underline{32}$. Ese mismo año se creó también una comisión para que propusiera un plan de construcción de cárceles federales "bajo un sistema convenientemente estudiado” $\underline{33}$. En las consideraciones, se afirmaba que el estado nacional contaba "con pocas cárceles para hacer cumplir las distintas penas que establece el Código Penal, y las provincias que no disponen de ellas acuden frecuentemente al Ministerio de Justicia y pidiendo la recepción de sus presos en estos establecimientos nacionales”. Asimismo, se agregaba que las cárceles, además de lugares de reclusión, debían ser "verdaderos reformatorios de provechosa enseñanza para la regeneración de los detenidos” y que, por consiguiente, requerían "edificios que permitan la clasificación y separación de los alojados según la falta o delito cometido y los antecedentes personales, 
para asegurar los resultados de la educación reformatoria”, a través del trabajo y la instrucción moral y religiosa.

El decreto finalizaba señalando que "para llenar las necesidades expuestas es conveniente confiar a una comisión de competentes, la preparación de un programa y de los planos que se someterán á la revisión del Departamento de Obras Públicas, el que determinará las sumas que sea necesario arbitrar para la ejecución de los trabajos”. Finalmente, se nombró una comisión conformada por Cornelio Moyano Gacitúa, ministro de la Corte Suprema, como presidente; José Luis Duffy, director de la Cárcel de Encausados, como secretario y, como vocales, Antonio Ballvé, director de la Penitenciaría Nacional; Armando Claros, director de la Colonia de Menores Varones de Marcos Paz; Catello Muratgia, director del Presidio de Ushuaia; Ramón Nieto Moreno, inspector general de cárceles; Carlos Altgelt, arquitecto del Ministerio de Justicia, y Miguel Olmos, ingeniero de la Dirección General de Arquitectura. Según el decreto, la comisión tenía plazo hasta diciembre de 1907 para remitir al Congreso un proyecto de construcción de cárceles y juzgados federales. En el tiempo transcurrido entre 1906 y 1907 se registró una gran actividad por parte del Inspector General de Cárceles, Nieto Moreno, quien fue enviado por el Inspector General de Justicia, Marco Avellaneda, a diferentes puntos del país para examinar las cárceles federales. Contamos con informes de Nieto Moreno sobre las cárceles de los territorios de Tierra del Fuego, Neuquén, Rio Negro, La Pampa, Misiones, Formosa y Chaco. Aparentemente, luego de cumplido el plazo de un año, la comisión se disolvió sin presentar un plan de construcciones.

En 1911, por iniciativa del ministro Garro, se creó una nueva comisión para redactar un proyecto de reforma integral del régimen carcelario federal. Como hemos mencionado anteriormente, los integrantes de la nueva comisión fueron Claros, director de la Penitenciaría Nacional, Muratgia, director del Presidio de Ushuaia, y Diego González, inspector general de Justicia.

\section{Muratgia y Claros, dos protagonistas de la reforma penitenciaria argentina ${ }^{34}$}

Catello Muratgia y Armando Claros fueron dos actores centrales de la reforma penitenciaria argentina y, sin embargo, se sabe muy poco de ellos $\underline{35}$. A continuación se realizan dos breves acercamientos biográficos a los autores del Proyecto de Reformas Carcelarias de 1912, mediante los cuales se intenta contribuir al conocimiento de los cuadros superiores de la administración penitenciaria argentina en tiempos “descentralizados”. Al final del apartado se ensayan algunas conclusiones, con base en la comparación de los orígenes y trayectorias de ambos funcionarios.

Claros nació en 1866 en San Salvador de Jujuy, en el seno de una tradicional familia del noroeste $\operatorname{argentino~} \underline{\underline{36}}$. Cursó sus estudios en la Universidad de Buenos Aires, donde obtuvo el grado de doctor en medicina en 1891 con una tesis titulada Sobre un caso de pseudo leucemia (Candioti, 1920, p. 931). Integrado a las filas del Partido Autonomista, se desempeñó dos veces como ministro de Gobierno de la provincia de Jujuy, durante la gobernación de Sergio Alvarado (1891-1893) y la de Manuel Bertrés (18951898). Al finalizar el gobierno de Bertrés fue electo diputado nacional por Jujuy, cargo que ejerció hasta 1902, cuando fue designado por el presidente Roca en el cargo de subsecretario del ministro del Interior Joaquín V. González. En cumplimiento de esas funciones participó de la exhumación de los restos de Belgrano para trasladarlos a la iglesia de Santo Domingo a un nuevo mausoleo erigido en su honor $\frac{37}{}$.

En 1904 Claros fue convocado junto a José Ingenieros, Pablo Storni, Carlos Malbrán, Leopoldo Lugones, Augusto Bunge, Manuel Ugarte y Enrique del Valle Ibarlucea para redactar los antecedentes fácticos y doctrinarios del proyecto de Ley Nacional del Trabajo, impulsado por Joaquín V. González. A fines de ese mismo año, al alejarse González del ministerio, Armando Claros dejó la subsecretaría y fue designado por 
Roca como vicedirector de la Dirección General de Correos y Telégrafos de la Nación $\underline{38}$.

Entre 1906 y 1909 Claros se desempeñó como director del Asilo Correccional de Menores Varones de la Capital $\underline{39}$. En 1909 asistió como delegado argentino al Congreso Penitenciario de Washington y a su regreso publicó su informe titulado Nuevas tendencias penales en el Congreso Penitenciario de Washington, que tuvo resonancia en los ámbitos científicos $\frac{40}{}$. En 1910 fue designado como director de la Penitenciaría Nacional y contribuyó con la revista Archivos de Psiquiatría y Criminología. Falleció el 21 de mayo de 1913, a los 47 años, en ejercicio de su función directiva $\underline{41}$. En su testamento dejó su biblioteca particular a la Biblioteca Popular de Jujuy (Sánchez de Bustamante, 1957, p. 373).

Muratgia nació en Nápoles, Italia, el 12 de agosto de 1861 (Petriella y Sosa Miatello, 2002). Cursó estudios de ingeniería en la Universidad de Nápoles y en 1883 se trasladó a la ciudad de Buenos Aires para trabajar como ingeniero de la recientemente federalizada ciudad y para la compañía de tranvías a caballo. En 1900 fue comisionado por el gobierno nacional a Tierra del Fuego para inspeccionar "las existencias del aserradero de la Cárcel de Reincidentes y confeccionar un presupuesto de los elementos y materiales necesarios para su completa reinstalación”, así como también para inspeccionar el aserradero que proponía a la venta Don Arturo Marcerral $\underline{42}$. En su estadía en la isla, Muratgia -que estaba en contacto con el presidente Roca y otros políticos interesados en establecer una colonia penal- $\underline{43}$ elaboró un plan de traslado de la cárcel de Ushuaia, inaugurada en 1896, a la bahía de Lapataia, donde se encontraba el aserradero de Marcerral. Dado el interés que generó con su propuesta, fue nombrado director de la cárcel ese mismo año $\underline{44}$. No obstante, sus planes de reubicar la cárcel se vieron obstaculizados por los pobladores de Ushuaia, quienes con no poca razón temían por la desaparición del poblado si la cárcel era trasladada. Muratgia accedió al pedido y en 1902 comenzó la construcción de una nueva prisión en el mismo lugar donde había funcionado la cárcel hasta entonces.

A partir de ese momento Muratgia se convirtió en un excepcional caso de funcionario comprometido en diseñar, construir y administrar un presidio a la vanguardia de la ciencia criminológica de la época. Con el trabajo de los mismos penados dirigió una colosal obra que incluyó desde la extracción de piedras de las canteras cercanas y la tala de enormes hayas de los bosques cercanos hasta su construcción en forma radial con cinco pabellones de dos niveles y gabinete de estudios antropométricos $\underline{45}$. Caimari sostiene que Muratgia convirtió a Ushuaia de un "depósito de incorregibles" a un "brillante faro de modernidad punitiva en el fin del mundo". Tan fuerte fue la personalidad de Muratgia que sus ambiciones criminológicas "apenas sobrevivirían a su gestión”, que se extendió de 1900 a 1909 (Caimari, 2004, p. 67). Durante su administración publicó dos libros: Breve estudio de la regeneración de delincuentes (1905) y Presidio y Cárcel de Reincidentes de Tierra del Fuego (1909). De regreso a la ciudad de Buenos Aires ya se había convertido en una eminencia en el tema penitenciario y fue convocado a dirigir la cárcel de encausados de la ciudad, cargo que ejerció entre 1911 y 1915. Falleció el 23 de noviembre de 1924.

La comparación entre las trayectorias de Claros y Muratgia depara algunas diferencias sustanciales en sus orígenes, aunque finalmente confluyeron sus caminos en la dirección de los establecimientos penitenciarios más importantes del país. Claros provenía de una familia tradicional jujeña, lo que implicaba una serie de contactos y redes de los que Muratgia carecía. Si bien Claros se doctoró en medicina en Buenos Aires, rápidamente se dedicó a la política en su provincia y fue ministro de gobierno a los 25 años. Durante diez años ocupó cargos públicos: fue dos veces ministro de Gobierno y una vez diputado nacional. En el ejercicio de la diputación jujeña Claros entró en contacto con la dirigencia nacional -en particular con Joaquín V. González- y al finalizar su mandato fue incorporado al Ministerio del Interior de la Nación. En ese mismo ministerio ocupó los cargos de subsecretario y luego vicedirector de Correos de la Nación. Posteriormente desconocemos la razón- recaló en la dirección del Asilo de Menores, a los 40 años, la misma edad a la que 
Muratgia comenzó a dirigir el presidio de Ushuaia.

Cuatro años más tarde, Claros ya había viajado al Congreso Penitenciario de Washington, había publicado su experiencia en ese encuentro y ocupaba la dirección de la cárcel más importante del país. Su inserción en las redes de estudios sobre los problemas penales se vio reflejada en la publicación de sus investigaciones en los Archivos de Psiquiatría y Criminología, la prestigiosa revista dirigida por José Ingenieros.

Muratgia, por su parte, carecía de las redes familiares que llevaron a Claros a las funciones públicas. Sin embargo, su condición de inmigrante calificado le permitió conseguir empleo estatal con rapidez. Luego de trabajar como ingeniero en Buenos Aires se vinculó rápidamente con el mundo penitenciario y recibió el encargo de diseñar y edificar el presidio radial que se convertiría en un ícono de la reforma en Argentina. Su acceso a un puesto clave en la administración penitenciaria fue más rápido que el de Claros, debido a que su función de director de obra se fusionó con la de director de ese espacio de reclusión. Debe recordarse que la cárcel fue levantada por los propios presos, razón por la cual el director de obra se convirtió rápidamente en la autoridad penal. El reconocimiento oficial de su trabajo y de su estudio -que se plasmó en sus librosculminó con su nombramiento en un puesto de importancia en Buenos Aires cuando la obra ya estaba casi terminada.

Tanto Claros y Muratgia como Ballvé, Duffy y otros directivos penitenciarios de la época fueron autodidactas en materia penitenciaria $\underline{46}$. Ninguno había tenido formación académica y, sin embargo, por sus trayectos profesionales en la función estatal y por sus obras publicadas -en las que relatan sus experienciasllegaron a ser referentes del penitenciarismo local. Como lo reconocían los propios expertos -Ingenieros entre ellos- el penitenciarismo era un campo de saber eminentemente práctico $\frac{47}{}$. Los casos que se estudian en este trabajo no constituyen excepciones en la administración penitenciaria argentina, sino que representan un tipo específico de "experto no académico", el penitenciarista "práctico" (González Alvo, 2016). La culminación del reconocimiento oficial a su labor en el área sería su nombramiento como miembros de la comisión de 1911.

\section{El Proyecto de Reformas Carcelarias de 1912}

Como se ha señalado anteriormente, los problemas edilicios así como la escasez de recursos y de personal, constituían los problemas más acuciantes de las cárceles del país. Sin embargo, los aspectos organizativos y fundamentalmente el tema de la centralización aparecían como cuestiones a resolver con premura. Los “conflictos de atribuciones” entre los directores y las comisiones de cárceles que aparecieron hacia 18901895 se produjeron también en los Territorios Nacionales entre los directores y los gobernadores, añadiendo una razón más para la creación de una administración centralizada de las cárceles federales $\underline{48}$. En 1911 se dio un paso hacia la centralización del servicio de guardia de los establecimientos federales con la creación del cuerpo de guardiacárceles de la Nación, por decreto del presidente Roque Sáenz Peña $\underline{49}$.

El 31 de diciembre de 1912, Claros, Muratgia y Diego González elevaron al ministro Garro el proyecto de reforma carcelaria que les fuera solicitado el año anterior. Los autores declaraban haber tomado como base teórica las ideas de las diferentes escuelas penitenciaristas que consideraron "más ventajosas y adecuadas a nuestras costumbres y al medio en que se actúa” $\underline{50}$. El proyecto se dividía en tres partes: consideraciones generales, firmadas por los tres miembros de la comisión; un plan de reorganización administrativa a cargo de Claros y un estudio sobre las necesidades edilicias, realizado por Muratgia.

En las consideraciones generales se recordaba la imperiosa necesidad de reformar el Código Penal de 1886 ya que, de lo contrario, sería “de todo punto imposible hacer nada bueno y completo” $\underline{51}$. También hacían referencia a la importancia de la implementación de la individualización del delincuente, de la condena y la 
libertad condicionales y de la pena sin término fijo $\underline{52}$. En cuanto a la individualización, la definían como un sistema basado en la división de los criminales según diferentes clases de crímenes, separación por edades y por reincidencia.

La reforma carcelaria, tal como la entendían los autores del proyecto, consistía en complementar el fin primordial de la pena -“la defensa social” $\underline{53}$ _ con la "regeneración del delincuente”. Asimismo, un régimen “moderno" debía garantizar a los procesados su total separación de los condenados, de manera que las cárceles no fueran escuelas del crimen. Las prisiones no debían ser solamente sanas y limpias, sino también espacios donde fuera posible hacer efectiva la reforma del culpable. Sobre los establecimientos carcelarios del país, el juicio de los miembros de la comisión fue lapidario: si se exceptuaba la Penitenciaría Nacional, en la Argentina no existían cárceles propiamente dichas $\underline{54}$. Incluso aquella adolecía de dos grandes defectos: su emplazamiento céntrico y su reducida capacidad para el flujo de penados de la Capital $\underline{55}$. Ante tal situación, recomendaban prescindir de todas las cárceles existentes (con excepción de la Colonia de Menores Varones de Marcos Paz) y construir una nueva cárcel de encausados en la Capital Federal y en cada territorio nacional. Los penados de todo el país serían conducidos a dos grandes penitenciarías regionales. La primera de ellas debía ser construida en Choele-Choel, Río Negro, y la segunda en el territorio nacional del Chaco, a 90 kilómetros de Resistencia, en el kilómetro 100 del ferrocarril de Barranqueras a Metán. Sobre las cárceles provinciales, que consideraban completamente inadecuadas -con excepción de la de Sierra Chica- los autores sugerían nacionalizarlas para que quedasen bajo la dirección de una autoridad central que dirigiera todos los establecimientos carcelarios, asilos y casas de detención del país.

Para concluir con sus consideraciones generales acerca de la aplicación de la reforma, los autores subrayaban que no era suficiente la construcción de establecimientos carcelarios y la aplicación de regímenes modernos. Aunque los penados hubieran "demostrado en sus actos una regeneración más o menos completa”, podían perderlo todo si "a la salida de la cárcel se encuentran librados a sus propias fuerzas". La acción penitenciaria debía continuar también luego de abiertas las puertas de sus establecimientos de reclusión. Para ello debían crearse instituciones que acompañaran al penado en su "nueva era de libertad” para evitar que se encontrara solo y aislado, "expuestos a todas las repulsas a que están sujetos todos aquellos que salen de la Cárcel Pública"ㅌ․

\section{Sistematización y centralización. La organización de las prisiones según Claros}

El estudio encomendado a Claros debía presentar un diagnóstico sobre la situación carcelaria argentina y plantear las bases para la organización de las cárceles federales. En su diagnóstico inicial, señalaba que era evidente que la Nación carecía de establecimientos suficientes y adecuados y que sus mejores cárceles Penitenciaría Nacional y Presidio de Ushuaia- estaban superpobladas. Los demás establecimientos no eran sino simples casas "que constituyen meros depósitos de presos, en hacinamiento malsano y promiscuidad corruptora” $\underline{57}$. No había espacios exclusivos para menores o encausados, los cuales acababan mezclándose con mayores de todas las edades, condenados y reincidentes. Hacia 1912 el hacinamiento era indiscutible: los condenados a prisión, penitenciaría y presidio sumaban 2.712, sin contar a los condenados por la justicia federal, que cumplían condena en establecimientos provinciales. A ese número debían agregársele aproximadamente unos 1.000 encausados, lo cual arrojaba una cifra cercana a los 4.000 hombres privados de libertad, cuando sólo se contaba con 1.300 celdas en todo el país.

La situación de la niñez, subraya Claros, no era menos alarmante. Mientras que la única dependencia estatal, la Colonia de Marcos Paz, tenía capacidad para 200 menores, la Defensoría de Menores tenía a cargo casi 1.000 niños más. Según los cálculos de Claros, unos 5.000 niños "pululan en las calles y suburbios, abandonados o huérfanos, a los que un urgente amparo detendría en su vida irregular y licenciosa” $\underline{58}$. 
También generaba alarma el aumento de la proporción de jóvenes y extranjeros en las prisiones: del total de personas que ingresaron a la Penitenciaría Nacional en 1911, 407 tenían entre 18 y 25 años y 484 eran extranjeros. Claros sostenía que para que la situación carcelaria no naufragase debía organizarse de manera sistemática, de manera que cada una de sus partes cumpliera un papel parcial dentro del conjunto que hacía a la institución. Un castigo moderno, agregaba, debía ser sistemático y dirigido a la regeneración y no a la satisfacción de pasiones irracionales $\underline{59}$. En el mismo camino que había abierto Lombroso, Claros decía que el castigo civilizado era aquel que "piensa y experimenta; cataloga los casos, observa, compara y concluye por dar reglas”. Entrado el siglo XX, continuaba el autor, el criminal ya no era visto simplemente como un ser atávico, nacido para el crimen, sino como "el producto fatal de factores que modelan el espíritu y su conciencia, y a cuyo impulso combinado obedece solamente” $\underline{60}$. No obstante, la avanzada de la ciencia penitenciaria ya no se encontraba en Europa, sino en Norteamérica, donde las experiencias de Filadelfia y Auburn habían sido reemplazadas por el sistema "reformatorio". Tal sistema, sostenía Claros, se basaba en las experiencias de Alexander Maconochie en Australia, Vladimir Sollogub en Rusia, Davenport Hill en Inglaterra y Walter Crofton en Irlanda.

Claros sostenía que los errores de los sistemas filadélfico y auburniano consistían en hacer del preso un solitario y privarlo de la palabra. Ambas políticas se equivocaban, puesto que desconocían que el hombre era un ser social y la vida celular "deprime las energías vitales” necesarias para combatir las tendencias criminales. Para Claros no había reforma sin una base de instrucción y educación moral, llevadas a cabo grupalmente. El reformatorio, concluía, era el sistema de la regeneración a través del ejemplo y la resocialización. Si bien sus éxitos eran aún parciales, sostenía, se habían comprobado nuevos progresos a través del régimen reformatorio. El preso sólo debía permanecer aislado en su celda en sus tiempos libres, relativamente escasos, entre el trabajo en el taller y el aprendizaje en la escuela. El condenado debía aprender un oficio o bien trabajar la tierra. Una penitenciaría no sería tal si no contemplara además del encierro celular, el trabajo en talleres, tierras cultivables y la enseñanza de las primeras letras, la moral y la religión.

La clasificación y separación de los reclusos debía llevarse a cabo teniendo en cuenta la edad y "los hábitos antisociales" específicos de cada uno de ellos, así como también la distinción entre "primarios" y reincidentes. Los procesados no debían desde ningún punto de vista habitar los mismos edificios que los penados. Debían construirse cárceles de encausados en cada juzgado y edificios de reforma para menores, al estilo de los detention home norteamericanos. Asimismo, sostenía que debía crearse un manicomio para “criminales locos” así como también un hospital para presos "infecciosos”, en particular tuberculosos. Sobre las mujeres, Claros sentenciaba que no podía deducirse del estado de la delincuencia femenina la necesidad de construir prisiones especiales para mujeres, ya que era "felizmente escaso" el porcentaje de delitos de la mujeres y más extraños aún los casos de niñas con condena.

Respecto a la construcción de nuevas prisiones, Claros sostenía que en los países de mayor experiencia, era ya un axioma que las prisiones comunes debían estar instaladas fuera de las grandes ciudades. Dentro de los radios urbanos no podía funcionar una prisión moderna, ya que su delicado cometido se vería afectado por el deseo de fuga que podía producir la ciudad, cuyos estridentes ruidos perturbarían la calma que debía reinar en la cárcel. Asimismo, trasladar a los recluidos a espacios poco poblados -como lo hacía Australia - podría redundar en el arraigo a la nueva tierra.

Surgía como resultado de su trabajo, según concluía el propio autor, la necesidad de crear una dirección nacional de prisiones representada por direcciones, superintendencias o comisiones que asumieran el control central de la administración penitenciaria. Finalmente, como una herramienta más de la regeneración, sostenía la necesidad de crear patronatos de excarcelados y de niños, al estilo de los hope halls norteamericanos, en los que se estimulaba la autodisciplina y el autogobierno. 


\section{El proyecto de construcciones de Muratgia}

Muratgia contribuyó al proyecto con un plan integral de construcciones penitenciarias estructurado en cinco capítulos. En los dos primeros sugería el número y clase de establecimientos necesarios para que el país siguiera los principios de la "ciencia penitenciaria moderna" y se refería sucintamente a los fundamentos científicos y económicos de su propuesta. Entre sus teóricos predilectos, citaba a André Michel Guerry, JeanCharles Herpin, Walter Crofton y Alexander Maconochie, adalides del sistema progresivo. Asimismo, reconocía el aporte de la obra de Luis V. Varela, Julio Herrera y, por último, mencionaba sus propios trabajos anteriores $\underline{61}$. En sus aportes previos, Muratgia ya había hecho hincapié en la misión terapéutica de la penitenciaría y cómo combatir el flagelo de la reincidencia en la Argentina.

Según Muratgia, a comienzos del siglo XX ya estaba demostrado de manera palmaria que el régimen carcelario más adecuado era el reformatorio, acompañado de un patronato de excarcelados. Para demostrarlo, el autor apelaba a un documento del siglo XIX que, por entonces, ya daba por sentado el triunfo del sistema reformatorio: las conclusiones del I Congreso Penitenciario Nacional estadounidense realizado en Cincinnati en 1870, antecedente directo del I Congreso Penitenciario Internacional llevado a cabo en Londres dos años después $\underline{62}$.

La gran mayoría de los hombres que delinquían podían enmendarse, sostenía Muratgia, y para conseguirlo se debían aplicar sistemas de premios y de gradual adquisición de la libertad, complementados con un patronato de liberados, para completar la tarea penitenciaria al reinsertar al "egresado de la prisión” y así evitar la reincidencia. Si bien estaba convencido de la importancia de la herencia, sostenía que nunca había compartido "la opinión de que el presidiario de raza anglosajona fuera más fácil de reformar” $\underline{63}$. Es interesante también la percepción de Muratgia de formar parte de un período de transición, al sostener que "las cárceles urbanas actuales serán en el porvenir la expresión de la época intermedia entre la bárbara y la civilizada” $\underline{64}$.

Con el fin de evitar el aumento de la criminalidad, propone construir tres tipos de construcciones "prepenitenciarias”. Primero, en las comisarías, edificar cárceles para contraventores preparadas para la formación de cuadrillas de trabajos municipales. En segundo lugar, erigir cuatro colonias nacionales para indigentes y, por último, construir cuatro "internados para pupilos", donde se establecieran tutorías sobre “menores abandonados o con padres incapaces” $\underline{65}$. En lo que respecta al tratamiento penitenciario propiamente dicho, dividía su proyecto entre medidas para menores y para mayores. Para los menores -tanto procesados como condenados- sugería dos tipos de construcciones: institutos correccionales de artes y oficios (tres para varones y uno para mujeres), y granjas nacionales agrícolas y ganaderas (para "menores condenados de buena clasificación”). Para el tratamiento de los adultos dividía su propuesta en instituciones para mujeres y para hombres. Para las mujeres sugería la construcción de un reformatorio de jóvenes de 18 a 30 años y una "prisión y penitenciaría” para mujeres mayores de 30 o con condenas severas.

En cuanto a los hombres, sugería la creación de diez prisiones nacionales para encausados y condenados a arresto -una en cada territorio nacional y en la Capital- y un reformatorio para jóvenes de 18 a 30 años con condenas cortas. En el otro extremo, para los hombres "completamente refractarios" al tratamiento penitenciario, “criminales natos e incorregibles”, proponía concluir el Presidio de Ushuaia y construir un “manicomio de penados”. El corazón de su propuesta se encontraba en la edificación de cuatro construcciones penitenciarias federales: dos cárceles penitenciarias regionales -norte y sur-, dos cárceles regionales -norte y sur-. El pasaje de una a otra institución dependería del progreso del penado, al punto que aquellos "mejor clasificados" podrían terminar sus condenas en colonias penitenciarias nacionales con una disciplina más laxa. Para que las cuatro construcciones respondieran al "tipo arquitectónico de la cárcel 
moderna” debían estar equipadas con talleres, escuela, capilla, gabinete de estudios psicológicos y médicolegales, salón de conferencias, enfermería, sala de cirugía y odontología y tierras cultivables. Su propuesta se apoyaba en numerosos estudios sobre construcciones penitenciarias europeas, entre los cuales menciona los de Karl Mittermaier, Guillaume Ferrus, Édouard Ducpétiaux, Luigi Fornasini, Martino Beltrani Scalia y Jean-Baptiste Stevens $\underline{66}$.

Concluía su propuesta con algunas precisiones sobre las construcciones que anteriormente había sugerido. En primer lugar, sostenía que todas las prisiones debían edificarse fuera del radio urbano y que no debían albergar más de 500 presos. Respecto a la distribución de los pabellones -a pesar de ser el autor del plano del Presidio de Ushuaia- fue uno de los primeros constructores de la Argentina en declarar perimido el partido radial $\frac{67}{2}$. Sostenía que en las nuevas prisiones sería preferible la construcción de pabellones aislados, paralelos o en grandes cuadrados antes que de tipo radial o en abanico. De esa manera, agregaba, habría más espacio entre cada pabellón, lo que facilitaría tanto la separación como la construcción de talleres y otras dependencias.

Todas las prisiones que se construyeran deberían guiarse por una misma regla para la ubicación de sus dependencias, muros y pabellones. Asimismo, con relación también al plano reglamentario, recomendaba la construcción de viviendas para los funcionarios más importantes de la prisión, de manera tal que los directores habitaran en la prisión rodeados por la residencia del subdirector, del alcaide y del médico. A continuación se ubicarían las oficinas administrativas, las cocinas, el comedor para empleados y el galpón de guardiacárceles. Entre aquellas construcciones y los pabellones mediarían dos muros de circunvalación separados entre sí por quince metros. El primer muro tendría nueve metros de altura, con cimientos de cinco metros de profundidad, y el segundo muro, seis metros de altura con igual cimentación. En el interior de los muros se levantarían de forma paralela o, en cuadrado, diez pabellones de cincuenta celdas. La escuela, los talleres, los depósitos, la capilla, la sala de conferencias y la enfermería formarían cuerpos separados por cincuenta metros entre sí y a igual distancia de los muros de circunvalación. Se dispondrían también unos veinticinco "calabozos de rigor" para cumplir las penas prescriptas en los reglamentos penitenciarios. Cada celda estaría equipada con cama, inodoro, timbre avisador, grifos, lámpara eléctrica, respiraderos, asiento y repisa.

Muratgia concluía con la idea de que para llevar a cabo el proyecto harían falta, aproximadamente, unos 52 millones de pesos, cifra que podía parecer exagerada pero que -en palabras de su autor- se acercaba mucho a la realidad y que, en un plazo de diez años, no consumiría más de 5,2 millones por año (1,4\% del total del presupuesto nacional de 1912 $)^{68}$. No obstante, se trataba de un monto elevado si consideramos que para el total de las obras públicas del país el presupuesto de 1912 destinaba 8,3 millones de pesos moneda nacional.

\section{Algunas consideraciones finales}

¿Disponen los comisionados de fuerzas estratégicas suficientes para servirse de la comisión y de todo lo que estaba implícito en la misión que se les encomendó para hacer respetar los resultados de su comisión?

¿Tienen la intención y la capacidad? Hay todo un trabajo empírico para hacer en cada ocasión, lo que no significa que el modelo no

siga siendo verdadero. El modelo está ahí para invitar a estudiar las variaciones de los parámetros (Bourdieu, 2014) 
Luego del recorrido realizado -primeras comisiones, trayectorias individuales y proyecto de reformas- es posible sostener algunas conclusiones parciales respecto de los orígenes del sistema penitenciario federal y de la conformación de sus cuadros superiores, así como también respecto del “fracaso” del proyecto de 1912, es decir, el hecho de que no haya sido llevado a la práctica.

Sobre las conclusiones parciales debemos señalar, en primer lugar, que las comisiones de 1890-1899 llevaron a cabo tareas completamente distintas a las de 1906 y $1911 \underline{69}$. Esto se puso en evidencia a fines del siglo XIX cuando la IGJ asumió las funciones de superintendencia que las comisiones habían cumplido en sus primeros años. Cuando volvieron a formarse comisiones en 1906 y 1911 ya perseguían otros objetivos que no consistían en supervisar las cárceles sino en proponer reformas. Para ello, ya no se acudió a los "ciudadanos idóneos”, sino directamente a los expertos: se convocaron juristas especializados en derecho penal y penitenciaristas "prácticos” como Muratgia y Claros. Mientras que las comisiones de la década de 1890 recordaban al penitenciarismo clásico, las de 1906 y 1911 fueron paralelas a las comisiones de revisión del código penal y persiguieron fines reformistas similares, inspirados por los ideales del cientificismo vigente. En segundo lugar, las comisiones de la década de 1890, aun habiendo sido reemplazadas por la IGJ, contribuyeron -aunque modestamente- a la centralización de la superintendencia de cárceles. Para comienzos del siglo XX, la IGJ supervisaba todas las cárceles federales y recomendaba el nombramiento o remoción de sus directores y personal subalterno $\underline{70}$.

En tercer lugar, el sucinto repaso biográfico de Claros y Muratgia demuestra que, aun proviniendo de orígenes disímiles, ambos culminaron compartiendo una serie de rasgos que también caracterizaron a otros altos mandos penitenciarios de la época “descentralizada” como O’Gorman, Ballvé o Duffy. Se trataba de autodidactas en materia penitenciaria, cuyos escritos sobre el tema -que tuvieron resonancia en su épocaprovenían de sus propias experiencias al frente de esas instituciones y no de estudios formales previos. Entusiastas hombres formados en la práctica, poseían un interés por la "cuestión penitenciaria” que los fue convirtiendo en figuras emblemáticas más por el reconocimiento de sus logros institucionales que por una trayectoria académica que los respaldase. Posteriormente, la centralización fue derivando -muy lentamenteen la profesionalización del acceso a los altos mandos.

Finalmente, en lo que respecta al Proyecto de Reformas Carcelarias (PRC), deben destacarse, al menos, dos aspectos. Los que conciernen a las innovaciones propuestas -el "régimen" y los conceptos edilicios- y las razones por las que no fue aplicado. En lo que respecta a las propuestas, debe destacarse la toma de posición de sus autores por el sistema progresivo, la cual quedó establecida al afirmar la urgencia de reformar completamente el Código de Tejedor. Sostenían que para aplicar el régimen reformatorio haría falta implementar la individualización del delincuente, la condena y la libertad condicionales, todos ellos componentes indispensables del sistema reformatorio. En segundo lugar, debe mencionarse la importancia que los autores concedían a la creación de una dirección nacional de prisiones que permitiera sistematizar los esfuerzos para la aplicación de medidas "profilácticas”, de la labor reformatoria y de la prevención de la reincidencia y la reinserción social de los "egresados” a través de patronatos de liberados. Finalmente, cabe destacar la planificación de renovación arquitectónica propuesta por Muratgia. Además de diseñar una forma homogénea para la construcción de todas las penitenciarías federales, es interesante señalar cómo el creador de una de las prisiones radiales más famosas del país comenzó a abogar por la construcción de pabellones paralelos, entendiendo que era la forma más correcta de aprovechar el espacio.

En lo que respecta a los resultados prácticos del $P R C$, debe señalarse -siguiendo a Bourdieu- que si bien los informes que las comisiones producen son discursos performativos y de autoridad deben ser analizados según la relación de fuerzas entre el mandante y el mandado y según la capacidad de ambas partes para hacer uso del informe (Bourdieu, 2014, pp. 44-45). Para poder conocer esa relación, Bourdieu sugiere indagar si 
los integrantes de la comisión poseen fuerza, intención y capacidad suficientes para hacer respetar los resultados de su dictamen. Para comprender los alcances de los informes de cada comisión debe realizarse un trabajo empírico, el cual intentamos llevar a cabo con el fin de comprender en qué medida las reformas propuestas fueron llevadas a cabo o no, y cuáles fueron los motivos en ambos casos.

Como se ha visto, la fuerza y capacidad de los comisionados para hacer cumplir los aspectos edilicios del $P R C$, fue casi nula. Debe decirse en este punto una obviedad: el plan era muy costoso. Aplicarlo en su totalidad hubiese implicado una erogación de casi el $20 \%$ del presupuesto anual nacional y aun pagado a lo largo de una década hubiera implicado destinarle anualmente el $60 \%$ del total destinado a todas las obras públicas del país. Esto explica el fracaso de la propuesta edilicia del proyecto. Sin embargo, otros aspectos fueron cumpliéndose con el tiempo y demostraron una mayor capacidad por parte de los comisionados $\underline{71}$. Es cierto que pasaron dos décadas, pero finalmente, mediante la Ley 11.833, de Organización Carcelaria y Régimen de la Pena, fueron llevados a la práctica dos aspectos centrales del PRC: la creación de una dirección general de institutos penales y la adopción del régimen progresivo.

\section{Notas}

1 Bourdieu ha analizado el trabajo de las comisiones -específicamente la "comisión Barre sobre la vivienda"- como una vía de acceso al estudio del Estado y la construcción social de los "problemas públicos” (Bourdieu, 2014).

2 A partir de 1880 se registra un esfuerzo sostenido del Estado Nacional para revertir la debilitación de la justicia federal producida por la reforma constitucional de 1860 y las leyes orgánicas de 1863 y 1878 que habían confiado a las provincias la aplicación ordinaria de los códigos nacionales habían excluido de la jurisdicción federal la libertad de imprenta y los recursos de fuerza y habían quitado a la Corte Suprema de la Nación la resolución de los conflictos entre los poderes públicos de una misma provincia y la de las causas entre una provincia y sus vecinos. (Zimmermann, 2007, pp. 288-289).

$\underline{3}$ Los Territorios Nacionales fueron creados durante la presidencia de Julio A. Roca, mediante la Ley 1.532 de Organización de los Territorios Nacionales (1884).

4 Memoria del Ministro de Justicia, Culto e Instrucción Pública, Tomo II, Buenos Aires, Taller Tipográfico de la Penitenciaría, 1887. En el presupuesto del ministerio de Justicia para 1890 se consignan sólo dos cárceles: la Penitenciaría (1.712.880 pesos m/n) y la Cárcel Correccional (268.800 pesos m/n). Ley del Presupuesto General de la República Argentina para el Ejercicio de 1890, Buenos Aires, Imprenta de SudAmérica, 1889, pp.301-305. En el presupuesto de 1892 se separa a la cárcel correccional de mujeres de la de menores varones. Ley del Presupuesto General de la República Argentina para el Ejercicio de 1892, Buenos Aires, Imprenta la Nueva Universidad, 1892, pp.157-159.

$\underline{5}$ Hacia 1897, los salarios de los directores de las diferentes cárceles federales revelaban una suerte de jerarquía entre los establecimientos. El salario más alto era el del director de la Penitenciaría Nacional con 600 pesos mensuales, seguido por los directores de la Cárcel Correccional de Varones y de la Cárcel de Reincidentes de Tierra del Fuego, con 350 pesos. En tercer lugar se ubicaban los directores de Chaco, Formosa, Misiones, La Pampa y Río Negro, con 130 pesos. El cuarto rango correspondía a los directores de Neuquén y Chubut, con 100 pesos. El último lugar lo ocupaba la "superiora” de la Cárcel Correccional de Mujeres de la capital, con 50 pesos. En la "comisión de cárceles” se empleaban 690 pesos mensuales: 250 para el secretario, 150 para el contador, 40 para el ordenanza y 250 para "gastos de oficina, traslación y alquiler del local”. Registro Nacional de la República Argentina, primer cuatrimestre de 1897, Buenos Aires, Taller tipográfico de la Penitenciaria Nacional, p. 257 (en adelante RNRA). 
$\underline{6}$ as memorias del ministerio de Justicia, en los apartados sobre el estado de las cárceles federales denuncian permanentemente los problemas edilicios. Memoria presentada al H. Congreso Nacional correspondiente a los años 1908-1909 por el Ministerio de Justicia e Instrucción Pública. Tomo I: Anexo de Justicia 19081909, Buenos Aires, Talleres gráficos de la Penitenciaría Nacional, 1910, pp. 772-854; Memoria de 1910, pp. 218-327 y en la Memoria de 1912, pp. 108-269.

Z La necesidad de una autoridad central venía evidenciándose desde fines del siglo XIX por los "conflictos de atribuciones" producidos entre las comisiones de cárceles y los directores. Algunas situaciones de este tipo se comentan en el siguiente apartado del presente trabajo.

8 Claros, Armando; González, Diego y Muratgia, Catello (1913), Proyecto de reformas carcelarias. Informe de la comisión especial, Buenos Aires, Talleres Gráficos de la Penitenciaría. Las referencias a esta obra se resumirán con las iniciales PRC (Proyecto de reformas carcelarias) seguidos del número de página de referencia. Por ejemplo, PRC, p.1.

9 La historia de la administración penitenciaria nacional puede dividirse en dos períodos netamente diferenciados: una etapa formativa entre 1880-1933, caracterizada por una administración descentralizada (bajo la supervisión del Ministerio de Justicia) y una segunda etapa de consolidación que comienza en 1933 y se caracteriza por la centralización derivada de la sanción de la ley 11.833 y la posterior creación del Servicio Penitenciario Federal.

10 Este trabajo se inscribe en el marco de una investigación más amplia -temática y cronológicamente- que ahondará sobre la construcción de los sistemas penitenciarios provinciales. Por esta razón otros aspectos que podrían complementar este escrito -como el examen de las tesis doctorales en jurisprudencia o las construcciones penitenciarias provinciales- serán desarrollados en etapas posteriores de la investigación mayor de la que el presente escrito forma parte.

11 Lila Caimari y José Daniel Cesano han estudiado las políticas penitenciarias federales durante el peronismo (2004, 2011). Jeremías Silva ha estudiado un período más amplio que incluye entre 1930 y 1955 (2012, 2013).

12 En tiempos del Centenario, la justicia federal todavía era considerada por algunos juristas como víctima de la reforma constitucional de 1860. En 1912, José Nicolás Matienzo denunció que la falta de centralización producía el mal funcionamiento del régimen federal (1912, p. 553). Matienzo consideraba que la reforma constitucional "había deformado trágicamente el sistema diseñado según el texto de 1853, introduciendo bajo la inspiración de un fuerte 'espíritu provincialista' una serie de restricciones y trabas a las facultades de los poderes nacionales que, en particular, habían debilitado a la justicia federal y acrecentado las jurisdicciones provinciales”, hipótesis que Corva corrobora en su estudio del poder judicial bonaerense (Corva, 2014). Tanto Matienzo como Rodolfo Rivarola sostuvieron que la crisis del sistema federal argentino se debía a la debilidad del sistema judicial. Ambos estaban de acuerdo en que los poderes provinciales constituían serios obstáculos en el proceso de "saneamiento institucional de la república". De esa manera, entendían que el fortalecimiento de la justicia federal y la centralización del aparato punitivo que de ella dependía eran pasos fundamentales en esa dirección.

13 Ballvé fue el responsable de la creación del Instituto de Criminología de la Penitenciaría en 1907 mientras que Duffy impulsó la Oficina de Estudios Médico-Legales del Asilo de Menores en 1905.

14 Los intentos de crear cárceles regionales o nacionalizar las penitenciarías provinciales aún no han sido objeto de un estudio específico. Son mencionados, sin embargo, en las obras de Levaggi (2002), Piazzi (2011), y González Alvo (2013). 
$\underline{15}$ "Decreto nombrando una Comisión encargada de proyectar la mejor forma de establecer en la Capital, las Casas de Corrección de Mujeres y menores”, 3 de septiembre de 1890 y "Decreto disponiendo que la reclusión de menores, se verifique en otro local distinto del que ocupan en la Cárcel Penitenciaría de la Capital”, Buenos Aires, 10 de septiembre de 1890. RNRA, segundo semestre de 1890, pp. 373-376.

16 Memoria del Ministerio de Justicia e Instrucción Pública. Año 1891, Talleres Gráficos de la Penitenciaría Nacional, Buenos Aires, 1891, p. xxii. Agradecemos al revisor/a anónimo por esta información. Ayerza se había doctorado en jurisprudencia en 1881 con la tesis Apuntes sobre el estudio del código rural, Udaondo se doctoró en medicina en 1883 con la tesis Ictericia y Roverano era un acaudalado hombre de negocios.

17 "Decreto aprobando las bases presentadas por la Comisión de Cárceles y Casas de Corrección, para la próxima licitación”, 31 de octubre de 1890. RNRA, segundo semestre de 1890, pp. 561-562.

18 RNRA, segundo semestre de 1890, p. 667; RNRA, primer semestre de 1891, p. 96.

19 RNRA, segundo semestre de 1891, p. 621. Emilio Martínez de Hoz falleció en julio de 1893 y fue reemplazado por Saturnino Martínez de Hoz. RNRA, primer semestre de 1893, p. 67.

20 RNRA, primer semestre de 1893, pp. 746-747.

21 RNRA, segundo semestres de 1893, pp. 150-151. Coelho renunció a la comisión investigadora en agosto y fue reemplazo por A. Reynal O'Connor. RNRA, segundo semestres de 1893, pp.158.

22 RNRA, segundo semestres de 1893, pp. 159.

$\underline{23}$ BORA, 10-08-1894.

$\underline{24}$ El representante argentino en el Congreso de Estocolmo fue Enrique Aberg. En el VI Congreso, celebrado en 1900 en Bruselas, asistió el ministro residente de Bélgica, Juan Carlos Belgrano. BORA, 27-04-1900.

$\underline{25}$ BORA, 15-05-1895. Originalmente el presidente de la comisión fue Aguirre aunque en julio de 1895 fue nombrado interventor de Santiago del Estero y fue reemplazado por Saubidet. BORA, 1895-07-25. Al terminar la intervención Aguirre retomó la presidencia de la Comisión hasta 1898. Juan Videla fue vicepresidente y Juan E. Barra, Eduardo Vidal y Fanor Velarde, vocales.

$\underline{6} 6$ "Acuerdo nombrando una Comisión ad-honorem encargada de correr con la construcción de los edificios de las cárceles y juzgados letrados de los territorios nacionales", RNRA, segundo semestre de 1895, pp. 829830.

$\underline{27}$ "Acuerdo autorizando a las comisiones encargadas de la construcción de edificios para las Cárceles y Juzgados Letrados de los Territorios Nacionales, de ajustar directamente las obras a efectuarse", RNRA, primer semestre de 1897, pp. 494-495.

$\underline{28}$ "Decreto constituyendo Comisiones honorarias para la vigilancia del régimen de las cárceles y control de racionamiento de los presos de los Territorios Nacionales”, RNRA, primer cuatrimestre de 1902, pp. 127128.

$\underline{29}$ En 1898, la ley 3.737 de “Organización de los Ministerios del Poder Ejecutivo” estableció que correspondía al ministerio de Justicia e Instrucción Pública "La creación, gobierno y reforma de las cárceles y establecimientos penales de la Nación”.

30 La Inspección General de Justicia fue creada el 21 de noviembre de 1893. El presupuesto de 1906 muestra la composición del IGJ: inspector general de justicia, inspector de cárceles, asilos y colonias correccionales de menores 400, secretario 200, cinco inspectores de sociedades, cárceles, juzgados, dos auxiliares, un 
escribiente y un ordenanza. El ministerio de Justicia publicó un libro en homenaje al centenario de su creación: Centenario de la Inspección General de Justicia, 1893 -21 de noviembre- 1993, Buenos Aires, Ministerio de Justicia de la Nación, 1993.

31 Contamos con pocos datos biográficos de Ramón Nieto Moreno, sabemos que trabajó 34 años en el Ministerio de Justicia, desde 1877 hasta 1911. BORA 09-03-1911.

$\underline{32}$ Según Jorge Núñez, en administraciones de la justicia como la francesa o española, el inspector general de cárceles era, en esta época, el tercer cargo en importancia, después del ministro de Gracia y Justicia y el director general (Núñez, 2014b, p. 5). En la Argentina, por el contrario, era un funcionario menor, cuyas atribuciones se limitan a inspeccionar las cárceles federales y elevar informes al inspector general de justicia, funcionario que responde directamente al ministro de Justicia e Instrucción Pública de la nación. No obstante, atendiendo a lo trabajado por Jeremías Silva, en los años '30 surgirá del seno del Ministerio de Justicia un cargo que se convertirá en antecedente directo de la ley 11.833: la Dirección e Inspección de Cárceles de los Territorios Nacionales. Creada por Acuerdo General de Ministros del 17 de noviembre de 1931, tuvo como director destacado a Juan José O’Connor quien, en 1933, impulsará el proyecto de ley sobre “Organización carcelaria y régimen de la pena” (Silva, 2012).

33 BORA, 1906-10-10.

$\underline{34}$ Recientemente se ha publicado un breve ensayo biográfico sobre Muratgia dentro de un estudio preliminar a la reedición de uno de sus libros (González Alvo y Núñez, 2015, pp. 11-40).

$\underline{35}$ Menos se conoce aún sobre Diego González, un importante funcionario del poder judicial de la Nación durante los primeros años de presidencia de Roque Sáenz Peña. En la obra de Marcial Candiotti figura la defensa de su tesis doctoral en jurisprudencia en el año 1866, titulada La forma del sumario en los procedimientos criminales es inconstitucional (Candioti, 1920, p. 778).

36 Armando Claros era hijo de José María Claros y Matilde González Portal. Sobre los enlaces matrimoniales entre la familia Claros y otras familias de las élites de Jujuy y Salta véanse los apéndices documentales del trabajo de Diez (2002). La madre de Armando Claros fue una de las primeras directoras de la Escuela Normal de Jujuy.

37 Diario La Nación, Buenos Aires, 05-09-1902. BORA, 31-10-1902.

38 BORA, 05-06-1904.

$\underline{39}$ Creada por decreto n 1.897 bajo la denominación de “Casa de Corrección de Menores Varones”, cambió de nombre en numerosas ocasiones. Todavía en pie, el edificio se encuentra en el barrio porteño de Parque de los Patricios, construido bajo el estilo neogótico. Al respecto, Claudia Freidenraij sostiene que cambió de nombre hacia 1901 "sin motivo aparente, pasando a denominarse Asilo de Reforma de Menores Varones. Sin embargo, las fuentes se referían a este establecimiento alternativamente como Casa de corrección, Asilo de reforma, e incluso 'prisión', 'cárcel de menores', 'correccional de niños’ de manera indistinta” (Freidenraij, 2011: 132).

40 La obra de Claros es alabada por Eusebio Gómez en su libro El problema penal argentino, Buenos Aires, 1912. Claros también es citado en numerosas ocasiones por Ingenieros al referirse a temas como prevención del delito, condena condicional, reformatorios de menores y patronato de liberados. Véase José Ingenieros, Criminología, Madrid: Daniel Jorro Editor, 1913. pp. 227, 236, 246, 251, 254. Los aportes de Claros también fueron tenidos en cuenta para la sanción del Código Penal de 1921. Véase capítulo sobre reincidencia. Otro importante penitenciarista argentino, Adolfo S. Carranza, adhiere a sus ideas en favor de la aplicación de la sentencia por tiempo indeterminado. Véase Adolfo S. Carranza, Estado de algunas cárceles en Europa. 
Portugal, España, Francia, Inglaterra, Bélgica, Alemania e Italia, Tucumán, Talleres Gráficos de La Gaceta, 1921. Asimismo, su obra es citada en la revista del Colegio de Abogados de Lima, Perú. Véase La Revista del Foro, Año XI, Junio y Julio de 1924, nº 6 y 7.

$\underline{41}$ En reemplazo de Armando Claros, se designó al exsenador nacional Manuel L. Padilla como director de la Penitenciaría Nacional. BORA, 27-05-1913.

42 BORA, 01-02-1900. p. 2493

$\underline{43}$ “Una vez fundado el establecimiento Penal en Tierra del Fuego, la República habrá puesto los cimientos de la colonización en ese punto". Lila Caimari recoge el proyecto presentado al Congreso durante la primera presidencia de Roca (1883) para describir el temprano anhelo estatal de erigir una nueva prisión en el extremo sur de la Argentina. Caimari aclara que se trata al mismo tiempo del "extremo sur del territorio reclamado por el gobierno argentino en el contexto de largas y complejas negociaciones limítrofes con Chile. En el telón de fondo de esta historia hay más de veinte años (1881-1902) de negociaciones sobre la definición del límite sur entre ambos países” (Caimari, 2000). Al menos desde 1876 el gobierno argentino había procurado establecer instituciones penales en la Patagonia (García Basalo, 1981).

$\underline{44}$ Por decreto presidencial del 24 de septiembre de 1900 se acepta la renuncia del primer director de la Cárcel de Reincidentes de la Tierra del Fuego, Pedro Della Valle, y se nombra, en su reemplazo, a Catello Muratgia. RNRA, tercer cuatrimestre de 1900, pp. 51-52.

45 Muratgia dirigió la obra hasta que renunció a la dirección del presidio en 1909. En concepto de honorarios por la confección de los planos y dirección técnica de los trabajos de edificación del presidio y cárcel de reincidentes de Tierra del Fuego, Muratgia recibió 15.000 pesos m/n. BORA, 1906-08-24. Era el equivalente a 30 sueldos de director del presidio.

46 José Luis Duffy, proveniente de la policía, asumió la dirección del Asilo Correccional de Menores en 1905. En 1907 publicó Cuestiones penales y penitenciarias, Buenos Aires, Tipografía de la Cárcel de

Encausados. En 1906 se dictó un decreto, a instancias de Duffy, para la creación del primer patronato de liberados oficial pero no llegó a ponerse en funcionamiento (Núñez, 2014a , p. 191)

47 Ingenieros, haciéndose eco de un artículo publicado por el jurista Eusebio Gómez en 1910, sostuvo que, en lo que se refería a la organización del trabajo, la Penitenciaría Nacional había "igualado a sus congéneres norteamericanas, gracias al progresista esfuerzo de Antonio Ballvé”, un penitenciarista "práctico". Ingenieros, José, Criminología, Madrid, Daniel Jorro Editor, p. 255.

$48 \mathrm{El}$ "Decreto reglamentando las relaciones de los Gobernadores con las autoridades judiciales de los Territorios Nacionales y estableciendo las subdivisiones internas de dichos Territorios” indicaba en su artículo

9: "La Superintendencia y gobierno superior de las cárceles y demás establecimientos penales o de corrección que la Nación sostiene en los territorios, y que por la Ley de 11 de Octubre de 1898, Art.11, corresponden al Ministerio de Justicia, se hará efectiva por intermedio del Gobernador, quien deberá concurrir con la Dirección de aquellos establecimientos, á mantener la disciplina, la seguridad, la higiene, el racionamiento regular, el buen régimen interno del mismo', y el patronato de los presos cuando recobren su libertad". Sobre las comisiones creadas en 1902, el artículo $10^{\circ}$ aclaraba que obrarían "como consejos consultivos del Director de la cárcel y del Gobernador del Territorio”. El racionamiento de los detenidos y su la traslación quedaba a cargo de la policía. RNRA, primer cuatrimestre de 1902, pp. 36-37

"Decreto estableciendo la superintendencia de los señores gobernadores de Territorios Nacionales sobre 
todos los empleados de la administración local”. “Art. $2^{\circ}$ : Esta superintendencia se refiere al mantenimiento del orden, disciplina, seguridad e higiene y a la observancia de los reglamentos a que están sujetos los Establecimientos y Oficinas Nacionales y las Cárceles de los Territorios”. RNRA, segundo trimestre de1911, pp. 17-18.

49 Considerando que el servicio de la guardia de cárceles contrariaba los fines de la Ley 4.707 (Ley Orgánica del Ejército) al hacer que los ciudadanos en servicio militar cubrieran la guardia y que "la índole del servicio de que se trata requiere de personal propio y estable”, el presidente Sáenz Peña decretó la creación de un cuerpo de 600 plazas para la vigilancia de los establecimientos carcelarios de la Nación. Luego nombró al coronel retirado, Rómulo Páez, como jefe del Cuerpo y al teniente coronel retirado Pedro A. Suárez como segundo Jefe. "Decreto creando el Cuerpo de Guardiacárceles de la Nación” y “Organizando el Cuerpo de Guardiacárceles”, RNRA, primer trimestre de 1911, pp. 174-175 y 184-185.

50 PRC, p. 9.

$\underline{51}$ PRC, p. 10.

$\underline{52}$ Los autores sostenían que se habían inclinado por la pena por tiempo indeterminado a pesar de que sobre esa materia no existía uniformidad de opiniones por parte de los penitenciaristas. Sin detallar las razones específicas, los autores basan su toma de posición en lo expuesto en el trabajo de Claros relativo al Congreso Penitenciario de Washington.

$\underline{53}$ PRC, p. 12. Sobre el concepto de defensa social en la Argentina, véase Suriano (1987), Zimmermann (1995) y Cesano y Muñoz (2010), entre otros.

$\underline{54}$ El presidio de Ushuaia no es mencionado ya que, además de estar en construcción, no es un lugar para la regeneración sino simplemente la contención de los reincidentes y “todos los de índole perversa y peligrosa”. PRC, p. 23. La principal historiografía de esta prisión está constituida por los trabajos citados de García Basalo y Lila Caimari.

$\underline{55}$ Respecto al fin del emplazamiento céntrico de las prisiones véase John Pratt (2006).

56 PRC, p. 24. Según Núñez, los patronatos de liberados procuraron atender a tres fines: “a) operar como un complemento de la reforma iniciada en la prisión; b) evitar la reincidencia de los liberados en el delito, a fin de reducir los índices de criminalidad y c) reinsertar socialmente al egresado de la prisión” (Núñez, 2010).

$\underline{57}$ PRC, p. 33.

$\underline{58}$ PRC, p. 35.

$\underline{59}$ Sobre la persistencia de las pasiones punitivas irracionales, David Garland afirma que, aun en la actualidad, "una vez afirmada la importancia de la racionalización en ciertos ámbitos del sistema penal, y habiendo sugerido sus efectos característicos, se hace necesario señalar los límites de este proceso y la persistencia de fuerzas no racionales e irracionales en la penalidad” (Garland, 199, p. 223)

60 PRC, p. 39.

61 Varela, Luis, Estudio sobre el sistema penitenciario, 1876; Herrera, Julio, La Reforma Penal, 1911 y Muratgia, Catello, Breve estudio sobre la regeneración de los delincuentes, 1905 y Presidio y Cárcel de Reincidentes Tierra del Fuego. Antecedentes, 1907.

62 Para un estudio sobre las participaciones latinoamericanas en los congresos penitenciarios internacionales véase Del Olmo, 1981 y Rivera Beiras, 2005. En 1914 se llevó a cabo el primer Congreso Penitenciario Nacional en Argentina. 
$\underline{63}$ Para un análisis de las ideas raciales y la reforma social en la Argentina véase Zimmermann, 1992 y Cesano, 2011.

64 PRC, p. 131. Esta concepción de eslabón civilizatorio de la penitenciaría del siglo XIX puede observarse muy bien desarrollada en Pratt, 2006.

$\underline{65}$ El pupilaje nacional interno se complementaría con un pupilaje "externo" para menores abandonados o con padres incapaces confiados a familias que se comprometen a educarlos con o sin remuneración. PRC, p. 137.

66 De la obra de Karl Mittermaier, es probable que Muratgia haya accedido a Der gegenwärtige Zustand der Gefängnissfrage (1860). Guillaume Ferrus (1784-1861) fue un psiquiatra francés, autor de Des prisonniers, de l'emprisonnement et des prisons (1850). Édouard Ducpétiaux (1804-1868), penitenciarista belga, fue uno de los autores europeos más prolíficos sobre esta materia. Autor de más de quince obras sobre las prisiones, Muratgia debe haber accedido a Des conditions d'application du système de l'emprisonnement séparé ou cellulaire (1857). Luigi Fornasini (1813-1893), médico italiano, autor de numerosas obras, entre las cuales la única referida a cárceles es Della riforma delle carceri voluta dalla morale, dalla politica e dalla igiene (1852). Martino Beltrani Scalia (1828-1909), penitenciarista italiano, fue autor de Lo stato attuale della riforma penitenziaria in Europa e in America (1874), fue además un gran impulsor del sistema progresivo irlandés en Italia. Comisionado por el gobierno italiano, Beltrani Scalia viajó en 1868 a Inglaterra e Irlanda para estudiar sus sistemas penitenciarios y, posteriormente, representó a su país en varios congresos penitenciarios internacionales. Jean-Baptiste Stevens fue el autor de De la Construction des prisons cellulaires en Belgique (1874).

$\underline{67}$ Acerca de la confusión entre las cárceles radiales y el proyecto de panóptico benthamiano, véase García Basalo, 2013a y 2013b.

$\underline{68}$ El presupuesto nacional de 1912 fue de 368.054.419 de pesos m/n. Ley de Presupuesto General para la República Argentina para el ejercicio de 1912, Buenos Aires, Talleres de Publicaciones de la Oficina Meteorológica Argentina, 1912, p. 3.

$\underline{69}$ También se ha observado en el desarrollo de este estudio un tercer tipo de comisión. Se trata de las comisiones que comienzan a funcionar en 1895 en cada territorio nacional bajo el nombre de "Comisiones de Construcción de Cárceles”. En 1902 son transformadas en Comisiones de Vigilancia y Construcción de Cárceles, pasando a ejercer una suerte de autoridad colegiada al ser integradas por los gobernadores, directores de prisión y jueces letrados.

$\underline{70}$ Atendiendo a lo señalado por Jeremías Silva, la creación de comisiones continuó hasta los años veinte y en algunos momentos retomó la superintendencia sobre los establecimientos de reclusión. En 1924 se creó por decreto del PE la Comisión de Superintendencia de Cárceles y Establecimientos de Corrección Nacionales, que tuvo bajo su jurisdicción a la Penitenciaría Nacional, la Cárcel de Encausados y el Asilo de Corrección de Mujeres de la Capital; el Presidio de Ushuaia y las cárceles de los Territorios Nacionales (Silva, 2012).

$\underline{71}$ También cabe mencionar que, a partir de entonces, no se construyeron más cárceles radiales en el país, tal como lo había indicado Muratgia, paradójicamente autor de la más célebre de ellas.

\section{Bibliografía}

Alonso, P. y Bragoni, B. (Eds). (2015). El sistema federal argentino. Debates y coyunturas (1860-1910). Buenos Aires: Edhasa. 
Barreneche, O. (2001). Dentro de la ley, TODO. La justicia criminal de Buenos Aires en la etapa formativa del sistema penal moderno de la Argentina. La Plata: Al Margen.

Bohoslavsky, E. (2005). Sobre los límites del control social. Estado, historia y política en la periferia argentina (1890-1930). En E. Bohoslavsky y M. Di Liscia (Eds.), Instituciones y formas de control social en América Latina, 1840-1940. Una revisión, pp. 49-72, Buenos Aires: Universidad Nacional de General Sarmiento, Universidad Nacional de La Pampa y Prometeo Libros.

Bohoslavsky, E. (2009). Cuestión criminal y respuestas estatales en áreas pampeano-patagónicas (18791930). En M. Sozzo (coord.), Historias de la cuestión criminal en la Argentina, pp.245-268, Buenos Aires: Editores del Puerto.

Bohoslavsky, E. y Casullo, F. (2008). La cárcel de Neuquén y la política penitenciaria argentina en la primera mitad del siglo XX. Nueva Doctrina Penal, pp. 295-314, Buenos Aires: Editores del Puerto.

Bourdieu, P. (2014). Sobre el Estado. Cursos en el Collège de France (1989-1992). Buenos Aires: Anagrama.

Caimari, L. (2004). Apenas un delincuente. Crimen, castigo y cultura en la Argentina, 1880-1955. Buenos Aires: Siglo XXI.

Caimari, L. (2000). Una sociedad nacional-carcelaria en la frontera argentina (Ushuaia, 1883-1947). Ponencia presentada en las Primeras Jornadas de Historia del Delito en la Patagonia, organizadas por el GEHiSo y las Facultades de Humanidades y de Derecho y Ciencias Sociales, General Roca.

Candioti, M. (1920). Bibliografía doctoral de la Universidad de Buenos Aires y catálogo cronológico de las tesis en su primer centenario: 1821-1920. Revista de la Universidad de Buenos Aires, año XVI, tomo XLIV.

Cesano, J. D. (2011). Conceptos instrumentales y marcos teóricos para una reconstrucción histórica del control social formal en la Argentina (1880 - 1955). Horizontes y Convergencias. Recuperado de http://www.horizontesyc.com.ar.

Cesano, J. D. y Muñoz, D. (2010). Inmigración, Anarquismo y Sistema Penal. Los discursos expertos de la prensa. Córdoba y Buenos Aires 1890-1910 (Protesta social, flujos migratorios y criminalización). Córdoba: Editora Alción.

Claros, A., González, D., y Muratgia, C. (1913). Proyecto de reformas carcelarias. Informe de la comisión especial. Buenos Aires: Talleres Gráficos de la Penitenciaría.

Corva, M. A. (2014). Constituir el gobierno, afianzar la justicia. El Poder Judicial de la provincia de Buenos Aires (1853-1881). Rosario: Prohistoria.

Del Olmo, R. (1981). América Latina y su criminología. Nueva criminología. México: Siglo XXI.

Diez, M. A. (2002). Instituciones territoriales, orden público y una ciudadanía en construcción: El Estado nacional y la formación de la Pampa Central (1884-1922). (Tesis doctoral). Recuperada de: http://www.memoria.fahce.unlp.edu.ar/tesis/te.132/te.132.pdf

Flores, V. (2015). Los inicios del sistema carcelario en el Territorio Nacional de la Pampa (1884-1930). Revista de Historia de las Prisiones, 1. Recuperado de http://www.revistadeprisiones.com/los-inicios-delsistema-carcelario-territorio-nacional-la-pampa-1884-1930-2/

Freidenraij, C. (2011). Hijos del rigor. Las vicisitudes del primer reformatorio argentino (Buenos Aires, fines del siglo XIX - principios del siglo XX). Revista Derecho y Ciencias Sociales, 5. Recuperado de http://sedici.unlp.edu.ar/handle/10915/15289 
García Basalo, A. (2013a). ¿Un panóptico en Buenos Aires? La primera penitenciaria proyectada en Sudamérica. Épocas: Revista de Historia, 8. Recuperado de http://p3.usal.edu.ar/index.php/epocas/article/view/2089

García Basalo, A. (2013b). La influencia chilena en la construcción del primer edificio penitenciario argentino. Trabajo presentado en las XIV Jornadas Interescuelas, Mendoza, Argentina.

García Basalo, A. (2017). Para seguridad y no para castigo: origen y evolución de la arquitectura penitenciaria. Tucumán: Instituto de Investigaciones Históricas Leoni Pinto.

García Basalo, J. C. (1981). La Colonización penal de la Tierra del Fuego. Buenos Aires: Servicio Penitenciario Argentino.

Garland, D. (1999). Castigo y sociedad moderna. México: Siglo XXI.

González Alvo, L. (2013). Modernizar el castigo. La construcción del régimen penitenciario en Tucumán, 1880-1916. Rosario: Prohistoria.

González Alvo, L. (2015). La reforma penitenciaria en 'el subtrópico de la república’ (Tucumán, Argentina, 1881-1927). Revista Pilquen, 18. Recuperado de https://dialnet.unirioja.es/servlet/articulo?codigo=5277349.

González Alvo, L. (2016). De ‘credo’ a ‘ciencia’: la construcción del penitenciarismo argentino. Derecho penal, criminología y saber penitenciario (1870-1945). Trabajo presentado en las jornadas "Crimen y Sociedad: diez años de estudios sobre policía, delito y justicia en perspectiva histórica”, Bariloche, Argentina.

González Alvo, L. y Núñez, J. (2015). Catello Muratgia (1861-1924) y la reforma penitenciaria argentina. Un ingeniero del mezzogiorno y la cárcel del fin del mundo. Breve estudio sobre la regeneración de los delincuentes. En reedición de Muratgia, Catello, Breve estudio sobre la regeneración de los delincuentes, pp.11-40, Córdoba: Buena Vista Editores.

Levaggi, A. (2002). Las cárceles argentinas de antaño (siglos XVIII y XIX). Teoría y realidad. Buenos Aires: Ad-Hoc.

Luciano, M. (2013). Las ideas penitenciarias en el campo jurídico cordobés. 1885-1911. Anuario de la Escuela de Historia Virtual, 4, Año 4. Recuperado de https://revistas.unc.edu.ar/index.php/anuariohistoria/article/view/8388

Luciano, M. (2014). La Penitenciaría de Córdoba: proceso de construcción, régimen interno y tensiones institucionales, 1887-1907. Prohistoria, 21, Año XVII. Recuperado de http://www.scielo.org.ar/scielo.php? $\underline{\text { script }=\text { sci arttext } \& \text { pid }=S 1851-95042014000100006}$

Matienzo, J.N. (1912). Ampliación de la justicia federal. Revista Argentina de Ciencias Políticas, Tomo IV.

Navas, P. (2009). Esos económicos brazos. El trabajo de los presos en la cárcel de Río Gallegos. Trabajo presentado en XII Jornadas Interescuelas/Departamentos de Historia, Bariloche, Argentina.

Navas, P. (2010a). Noticias de la Cárcel... El penal de Río Gallegos a través del periódico La Unión. Trabajo presentado en IV Jornadas de Historia de la Patagonia, Universidad Nacional de La Pampa.

Navas, P. (2010b). El sinuoso camino hacia la profesionalización. El caso de los Guardiacárceles de la Unidad Penitenciaria $N^{\circ} 15$ de Río Gallegos (1904-1932). Trabajo presentado en IV Jornadas de Historia de la Patagonia, Universidad Nacional de La Pampa, Santa Rosa, Argentina. 
Navas, P. (2012). La construcción de soberanía y el control social en la periferia patagónica desde la cárcel de Río Gallegos (1895-1957). (Tesis doctoral), Universidad Nacional de La Plata, La Plata, Argentina. Recuperado de http://sedici.unlp.edu.ar/handle/10915/30750

Núñez, J. (2010). Notas para el estudio de los patronatos de liberados y excarcelados de las prisiones de España y la Argentina (1890-1918). Revista de Historia del Derecho, 39.

Núñez, J. (2014a). La reinserción social de los ex-presidiarios en la Argentina de las primeras décadas del siglo XX. Algunos comentarios biográficos sobre Jorge H. Frías, fundador del Patronato de Liberados y Excarcelados de la Capital Federal. Temas de Historia Argentina y Americana, XXII. Recuperado de: http://bibliotecadigital.uca.edu.ar/repositorio/revistas/reinsercion-social-ex-presidiarios-argentina.pdf.

Núñez, J. (2014b). Fernando Cadalso y Manzano: Medio siglo de reforma penitenciaria en España (18591939). (Tesis doctoral) .Universidad de Valladolid, España.

Petriella, D. y Sosa Miatello, S. (2002). Diccionario Biográfico Ítalo-Argentino. Buenos Aires: Dante Alighieri.

Piazzi, C. (2011). Justicia criminal y cárceles en Rosario (Segunda mitad del siglo XIX). Rosario: Prohistoria.

Pratt, J. (2006). Castigo y civilización. Una lectura crítica sobre las prisiones y los regímenes carcelarios. Barcelona: Gedisa.

Rivera Beiras, I. (2005). Política criminal y sistema penal: viejas y nuevas racionalidades punitivas. Barcelona: Anthropos.

Salvatore, R. (1996). Penitentiaries, Visions of Class, and Export Economies: Brazil and Argentina Compared. En R. Salvatore \& C. Aguirre (Eds.), The Birth of the Penitentiary in Latin America: Essays on Criminology, Prison Reform and Social Control. Austin: UTP.

Salvatore, R. \& Aguirre, C. (1996). The Birth of the Penitentiary in Latin America. Essays on Criminology, Prison Reform, and Social Control, 18301940. Austin: UTP.

Sánchez de Bustamente, T. (1957). Biografías históricas de Jujuy. Tucumán: UNT.

Silva, J. (2012). Formación de los cuadros menores de la administración del castigo (1945-1955). En K. Ramacciotti y C. Biernat (Eds.). Políticas sociales, entre demandas y resistencias: Argentina, 1930-1970, pp.123-148,Buenos Aires: Editorial Biblos.

Silva, J. (2012). Las políticas penitenciarias del estado nacional entre 1930 y 1960. En Actas de las VII Jornadas de Sociología de la Universidad Nacional de La Plata "Argentina en el escenario latinoamericano actual: debates desde las ciencias sociales”. La Plata, Argentina.

Silva, J. (2013). El sistema penitenciario del Estado nacional entre 1930 y 1943. En R. Salvatore y O. Barreneche (Eds.). El delito y el orden en perspectiva histórica. Rosario: Prohistoria.

Suriano, J. (1987). Trabajadores, anarquismo y Estado represor. De la Ley de Residencia a la Ley de Defensa Social (1902-1910). Buenos Aires: CEAL.

Zimmermann, E. (1995). Los liberales reformistas. La cuestión social en la Argentina, 1890-1916. Buenos Aires: Sudamericana.

Zimmermann, E. (2007). Centralización, Justicia Federal y construcción del Estado en la Organización Nacional. Revista de Instituciones, Ideas y Mercados, 46. Recuperado de 
http://www.eseade.edu.ar/files/riim/RIIM 46/46 10 zimmermann.pdf 